\title{
ESTIMATION OF RUNOFF FOR THE WATERSHED USING SCS-CURVE NUMBER METHOD AND GIS
}

\author{
C. H. RADHA SRIVALLI ${ }^{1} \&$ MANJEET SINGH ${ }^{2}$ \\ ${ }^{I}$ P. G Student, Department of Soil and Water Engineering, CTAE, Udaipur, Rajasthan, India \\ ${ }^{2}$ Assistant Professor, Department of Soil and Water Engineering, CTAE, Udaipur, Rajasthan, India
}

\begin{abstract}
Runoff is the most important factor considered in watershed management, which depends mainly on the physiographic characteristics of the watershed. In this paper, Estimation of runoff Potential is carried out for Gadela watershed located in Udaipur district, Rajasthan by the most popularly used SCS-Curve number approach, along with GIS. The watershed is delineated and divided into 10 sub basins, using Arc GIS to find the runoff from each sub basin. To calculate the runoff depth, the rainfall of the area from 1994-2014 for 20 years is considered. The thematic maps such as Land use/ Land cover and soil map, were prepared in the Arc GIS environment and overlaid to find the Curve number values. The yearly and basin wise runoff was calculated and presented in the graph. The results found that, runoff depth was more during 2006, which is about $62 \%$ of the total average rainfall of 650mm and less runoff in 1998, which is $22 \%$. The average runoff in the watershed basin wise was $115.96 \mathrm{~mm}$, of the average rainfall $535.65 \mathrm{~mm}$. The sub basin 10 was having the highest runoff, followed by basin 6 and basin 9 and the lowest runoff observed in Sub basin 1 and the Sub basin2. The reason for the runoff from a watershed is, due to the presence of cultivated area about $54.2 \%$ of the total area, Scrub land of $44 \%$ and forest area only $0.6 \%$.

KEYWORDS: Arc GIS, Rainfall, Runoff, SCS-Curve Number \& Thematic Maps
\end{abstract}

Received: Aug 13, 2017; Accepted: Aug 16, 2017; Published: Aug 30, 2017; Paper Id.: IJASROCT201712

\section{INTRODUCTION}

The growth of the global population requires effective utilization of dwindling natural resources, especially for agricultural and livelihood needs. Natural resource development programs are generally applied on a watershed level (Khan, 2001). Watershed is an entity, which helps to dispose the runoff through a single outlet. Runoff is the process which takes place after satisfying the abstraction losses the excess water that goes down without being used for any purpose, due to steep slope and stones in the soil causing soil erosion and converted into degraded land. SCS-CN provides an empirical relationship, for estimating initial abstraction and runoff as a function of soil type and land-use. Curve Number (CN) is an index, developed by the Natural Resource Conservation Service (NRCS), to represent the potential for storm water runoff within a drainage area. (Ashish, 2014).

\section{STUDY AREA}

The Gadela Watershed is located in the Udaipur district, which falls under Agro-climatic zone IVA Sub humid region of Rajasthan. The study area is bounded by $73^{0} 30^{\prime}$ to $74^{\circ} 15^{\prime}$ E Longitude and $24^{0} 30^{\prime}$ to $25^{\circ} 0^{\prime} \mathrm{N}$ Latitude covering Survey of India(SOI) topo sheets of 45H-13,14 and 45L-1, 2 and 9 of 1:50,000 scale. The average rainfall of the study area in monsoon is $535 \mathrm{~mm}$, with average number of rainy days $31 \mathrm{in}$ a year. The major 
soils in the area are Coarse loamy and Loamy Skeltel, which comes under Hydrologic Soil group B.

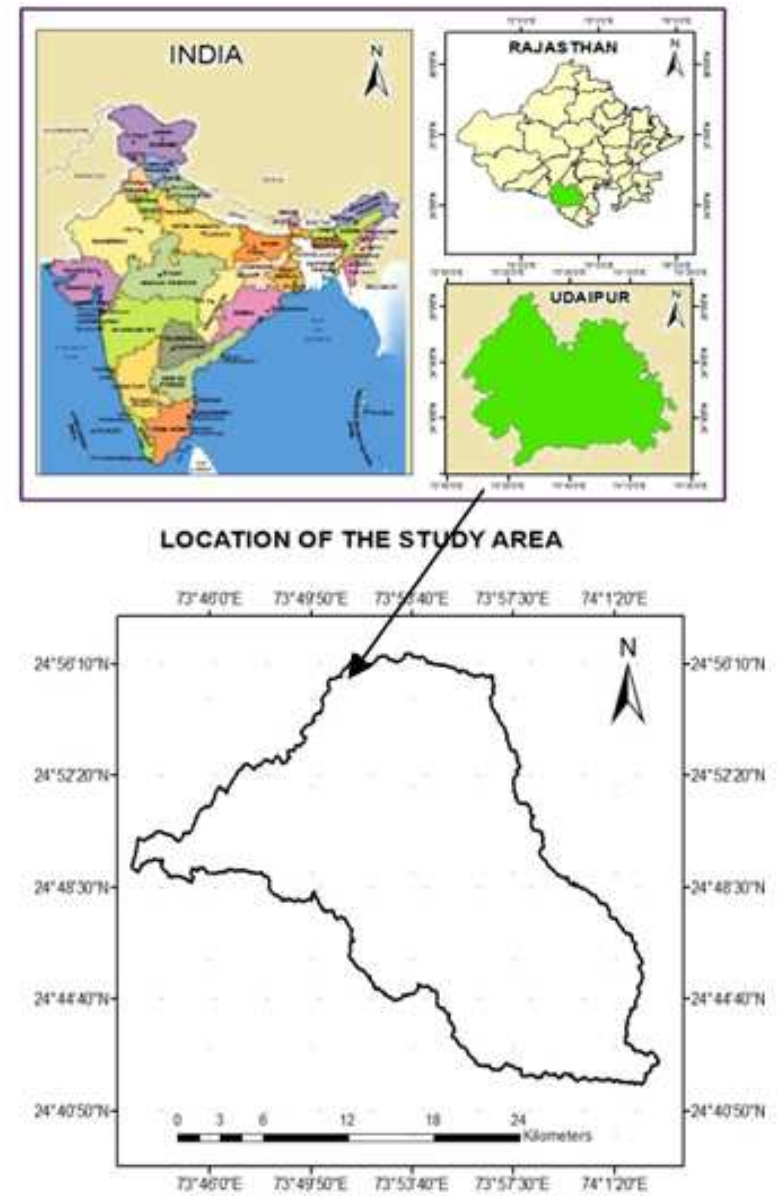

Figure 1: Location of the Gadela Watershed

\section{METHODOLOGY}

The rainfall data of the area from 1994-2014, was obtained from Water resource department Rajasthan and the thematic maps Land use/ Land cover image by LISSIII, was downloaded from bhuvan.nrsc.in. The soil map of the study area obtained from NBSSLUP (National Burea of Soil Survey and Land use Planning) was used in Arc GIS, to delineate the soil map of the study area. The watershed was divided into $10 \mathrm{Sub}$ basins and the runoff of the area studied by using SCS-Curve number method. The SCS approach involves the use of simple empirical formulas and readily available tables and curves, developed by the Soil Conservation Service (SCS, 1985). The area consists of cultivated land, Scrub, Barren, Fallow, Forest area and Water bodies, shown in Figure 2. The curve number values are obtained by considering Antecedent rainfall, Land use and Soils of the area. The SCS runoff expressed in unit depth, spread over the watershed for Indian conditions is given by

$$
Q=\frac{(P-0.2 S)^{2}}{P+0.8 S}
$$

Where,

$\mathrm{Q}=$ Direct flow volume depth, $\mathrm{mm}$ 
$\mathrm{P}=$ total rainfall, $\mathrm{mm}$

$\mathrm{S}=$ Potential Maximum soil retention

Curve number value is used to estimate the Potential maximum retention(S)

$$
S=\frac{25400}{C N}-254
$$

These table values are applied, only to AMC-II and in order to derive curve number values, for AMC-III the following Correction factors need to be applied (Rao et al., 2010).

$\mathrm{CNIII}=1.95 * \mathrm{CNII} * \exp (-0.00663 * \mathrm{CNII})$

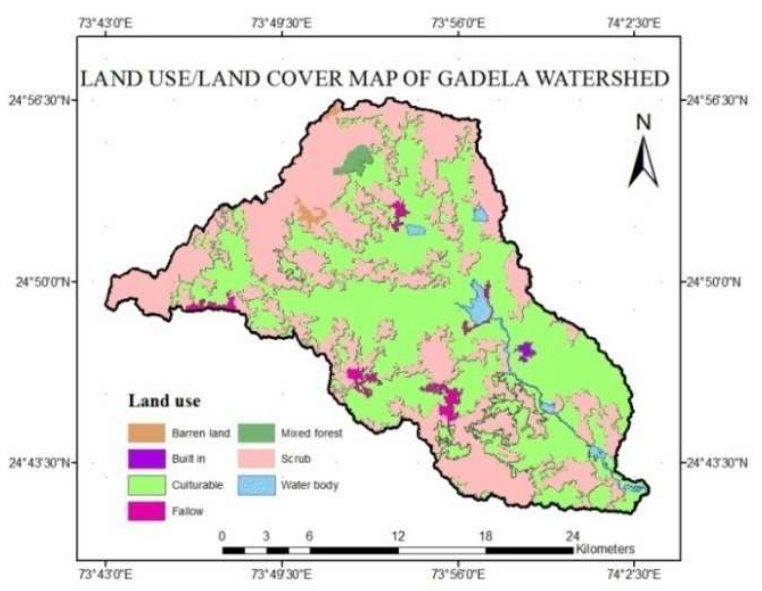

Figure 2: Land Use Map of the Gadela Watershed

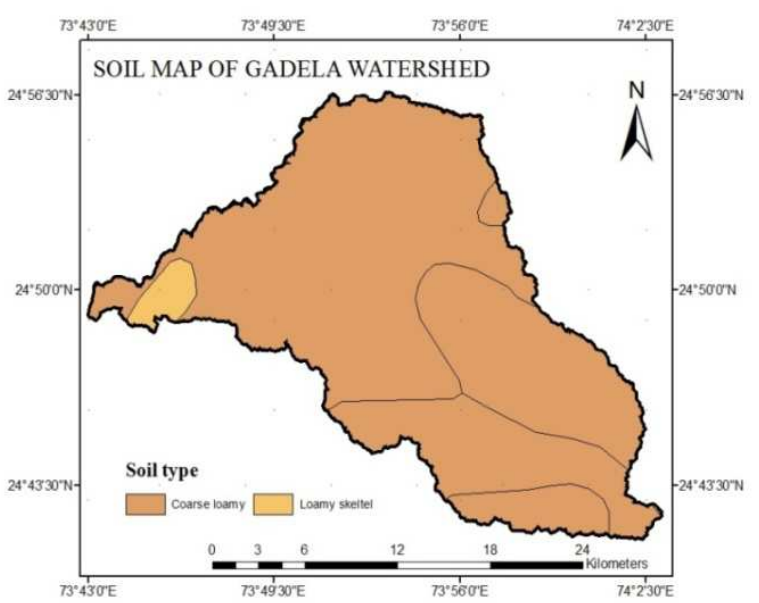

Figure 3: Soil Map of the Gadela Watershed

The curve number values adopted for the study area and AMC conditions, were presented in Table 1 and Table 2.

Table 1: Classification of Antecedent Moisture Conditions (SCS, 1986)

\begin{tabular}{|c|c|c|}
\hline AMC & Dormant Season & Growing Season \\
\hline I & $<12.5$ & $<35$ \\
\hline II & 12.5 to 27.5 & 35 to 52.5 \\
\hline III & $>27.5$ & $>52.5$ \\
\hline
\end{tabular}


Table 2: Curve Number Values for Land Use and Soil Classes

\begin{tabular}{|c|l|c|c|}
\hline S No. & Land Use & Soil Group & Curve Number \\
\hline 1 & Forest & B & 63 \\
\hline 2 & Agriculture & B & 78 \\
\hline 3 & Scrub land & B & 67 \\
\hline 4 & Barren & B & 75 \\
\hline 5 & Fallow land & B & 86 \\
\hline 6 & Built up land & B & 85 \\
\hline 7 & Water body & B & 94 \\
\hline
\end{tabular}

\section{RESULTS AND DISCUSSIONS}

The monsoon rainfall data from 1995-2014, was collected from the water resource department, Rajasthan and used to find out the runoff from the watershed. The calculated average runoff depth for 20 years was found to be as $184.04 \mathrm{~mm}$. The maximum runoff of the watershed was observed during 2006, which was about $62 \%$ of the total rainfall and minimum runoff found in 1999 about 18\%. The average runoff for the watershed basin wise was $184.39 \mathrm{~mm}$ of the average rainfall $535.65 \mathrm{~mm}$. The sub basin 10 was having the highest runoff of $195.02 \mathrm{~mm}$, followed by basin 6 of 194.83mm and basin 9 with $192.05 \mathrm{~mm}$. The lowest runoff has been observed in basin 1 with $172.09 \mathrm{~mm}$ and the basin 2 having $171.16 \mathrm{~mm}$. The variation of direct runoff depth $(\mathrm{mm})$ for basins and Yearly runoff depth were presented in the Figure 4 and Figure 5. The change in land use is considered to be the major factor, in causing surface runoff. Dense vegetation cover facilitates low surface runoff conditions, whereas sparse vegetation and bare surface was having relatively high runoff. It was observed that, Sub basin 10 having the highest runoff due to more percentage area covered in the basin by scrub with sparse vegetative cover and cultivated land. The lowest runoff observed in basin 2 may be due to the presence of forest cover and basin 1 have been covered by Phyllite and schist, which was good in terms of infiltration, which may be the reason for the lowest runoff observed. The calculated runoff values yearly and basin wise were presented in Table 3 and Table 4.

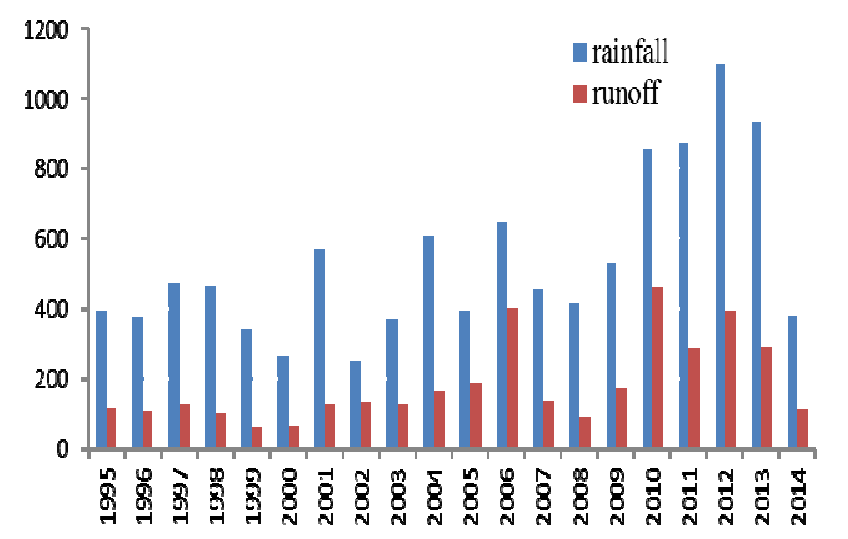

Figure 4: Yearly Runoff Estimated for Gadela Watershed 


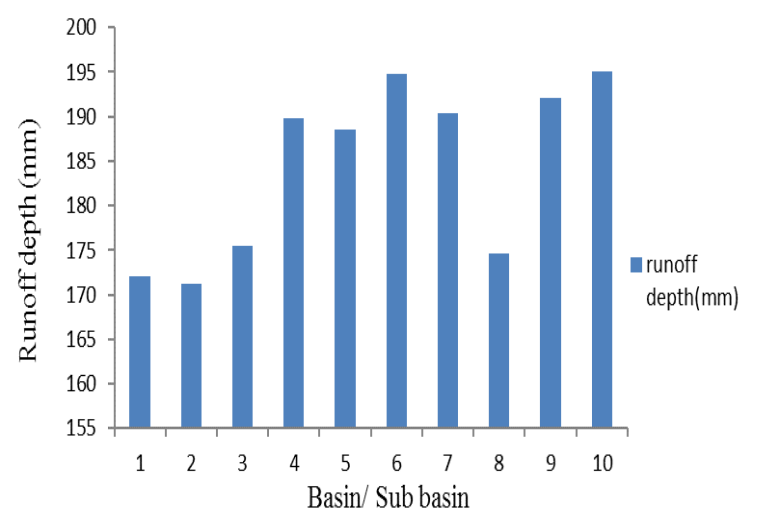

Figure 5: Basin Wise Runoff Estimated for Gadela Watershed

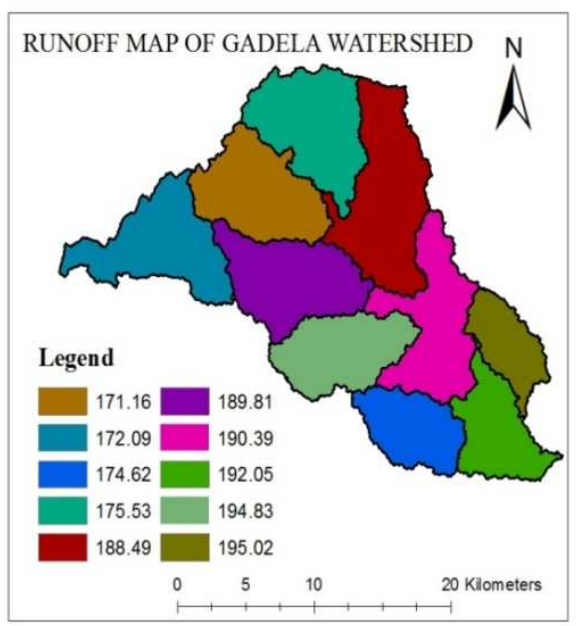

Figure 6: Runoff Map of Gadela Watershed

Table 3: Yearly Runoff Depth (mm) for Gadela Watershed (1995-2014)

\begin{tabular}{|c|c|c|c|c|}
\hline S No. & Year & Rainfall, mm & Runoff mm & Runoff $\%$ \\
\hline 1 & 1995 & 397 & 117.22 & 30 \\
\hline 2 & 1996 & 376 & 11.36 & 30 \\
\hline 3 & 1997 & 467 & 126.62 & 27 \\
\hline 4 & 1998 & 476 & 100.98 & 22 \\
\hline 5 & 1999 & 343 & 62.29 & 18 \\
\hline 6 & 2000 & 266 & 65.73 & 25 \\
\hline 7 & 2001 & 570 & 128.10 & 22 \\
\hline 8 & 2002 & 250 & 135.39 & 54 \\
\hline 9 & 2003 & 369 & 126.62 & 34 \\
\hline 10 & 2004 & 610 & 166.43 & 27 \\
\hline 11 & 2005 & 397 & 190.80 & 48 \\
\hline 12 & 2006 & 650 & 401.74 & 62 \\
\hline 13 & 2007 & 454 & 137.54 & 30 \\
\hline 14 & 2008 & 415 & 92.78 & 22 \\
\hline 15 & 2009 & 530 & 171.40 & 32 \\
\hline 16 & 2010 & 856 & 463.56 & 54 \\
\hline 17 & 2011 & 871 & 286.02 & 33 \\
\hline 18 & 2012 & 1101 & 395.25 & 36 \\
\hline 19 & 2013 & 933 & 292.8 & 31 \\
\hline 20 & 2014 & 382 & 115.96 & 30 \\
\hline \multicolumn{2}{|c|}{ Average } & $\mathbf{5 3 5 . 6 5}$ & $\mathbf{1 8 4 . 0 4}$ & $\mathbf{3 3 \%}$ \\
\hline
\end{tabular}




\section{CONCLUSIONS}

The yearly runoff depth calculated from 1995-2014 has shown that, of the $535.65 \mathrm{~mm}$ average rainfall, $184.04 \mathrm{~mm}$ going as runoff, which is about $33 \%$, that can be conserved by suitable structures in the watershed. The runoff depth (mm) calculated for different sub basins shows that, basin 6 and 10 are having highest runoff of $194.83 \mathrm{~mm}$ and $195.02 \mathrm{~mm}$, respectively, followed by basin 9 and basin 7. From the study it was found that, GIS is an efficient tool in calculating the runoff, by preparing the different thematic maps within less time.

Table 4: Basin Wise Weighted Curve Number and Runoff Depth

\begin{tabular}{|c|c|c|c|}
\hline \multirow{2}{*}{ Basin/Sub Basin } & \multicolumn{2}{|c|}{ Weighted Curve Number } & \multirow{2}{*}{ Runoff Depth, mm } \\
\cline { 2 - 3 } & CNIII & CNII & \\
\hline 1 & 85.53 & 72.0 & 172.09 \\
\hline 2 & 84.80 & 70.8 & 171.16 \\
\hline 3 & 85.37 & 71.7 & 175.53 \\
\hline 4 & 87.38 & 75.1 & 189.81 \\
\hline 5 & 87.21 & 74.8 & 188.49 \\
\hline 6 & 87.51 & 75.3 & 194.83 \\
\hline 7 & 87.95 & 76.0 & 190.39 \\
\hline 8 & 84.51 & 70.3 & 174.62 \\
\hline 9 & 87.51 & 75.3 & 192.05 \\
\hline 10 & 88.01 & 76.1 & 195.02 \\
\hline
\end{tabular}

\section{REFERENCES}

1. Ashish Bansode, K. A. Patil, 2014. Estimation of Runoff by using SCS Curve Number Method and Arc GIS. International Journal of Scientific \& Engineering Research, 5(7):1283-1287.

2. Khan M. A, Gupta V. P and Moharana P. C, 2001. Watershed Prioritization using Remote Sensing and Geographical Information System- A Case Study from Guhiya. India. J. Arid Environ, 49:465-475.

3. Pratibha Katara, Deepesh Machiwal, H. K. Mittal, Yogita Dashora and Arun D. Bhagat, 2013. Estimation of runoff for Arhar river Catchment in Udaipur district Integrated Remote sensing and Geographical Information system. Research Gate. PP: 169-175.

4. Rao. K, Singh K. D,(2006) Sustainable development of land and water resources using Remote Sensing and GIS, Journal of Indian society of Remote Sensing Vol-34, pp 223-229. 